\title{
Acute Ischemic Stroke Management-The Updated 2018 Stroke Guidelines
}

\author{
Ozgur Sogut (1) \\ Department of Emergency Medicine, Health Sciences University Haseki Training and Research Hospital, Istanbul, Turkey
}

Cite this article as: Sogut O. Acute Ischemic Stroke Management-The Updated 2018 Stroke Guidelines. Eurasian J Emerg Med. $2018 ; 17$ (3): 89.

\section{Dear Editor,}

Following publication of the 2013 Stroke Guidelines, revisions were made to the 2015 update after publication of randomized clinical studies with high levels of evidence. The 2018 guidelines on the early management of patients with ischemic stroke containing these revisions were provided online as an epub ahead of print on January 24, 2018, and were published in the March 2018 issue of Stroke (1). The DAWN (January 4, 2018) and DEFUSE-3 (February 22, 2018) studies published in The New England Journal of Medicine just before the release of the new guidelines prompted important revisions in the 2018 Stroke Guidelines $(2,3)$. In the DAWN study, among patients with acute stroke lastknown to be well 6-24 hours previously among patients with acute ischemic stroke who known to be well between 6 and 24 hours, and who had a discrepancy between the clinical deficit and infarct volume, the 90-day neurological outcomes were better in patients who underwent thrombectomy and were given standard care than in those who received standard care only (2).

As a novel recommendation, the updated guidelines have widened the time window (6-24 hours after stroke onset) and patient criteria for mechanical thrombectomy among patients with acute ischemic stroke (1). In the updated guidelines, mechanical thrombectomy is recommended for selected cases with acute ischemic stroke within 6-16 hours after symptom onset among patients with large-vessel occlusion in the anterior circulation who meet the other criteria specified in DAWN (discrepancy between clinical presentation and infarct volume) or DIFFUSE-3 (ischemic tissue volume/infarcted tissue volume $\geq 1.8$; perfusion/diffusion mismatch $\geq 1.8$ ) (Class I, Level of Evidence A) (1-3). The guidelines also state that for selected cases with acute ischemic stroke, it is reasonable to perform mechanical thrombectomy within 6-24 hours after symptom onset among patients with large-vessel occlusion in the anterior circulation who meet the DAWN patient appropriateness criteria (Class Ila, Level of Evidence B) (1, 2).

In conclusion, the updated guidelines emphasize that effective stroke treatment be provided as soon as possible and measures to prevent stroke recurrence be taken. They stressed that stroke training programs should be provided for various racial, age, and gender groups. The updated guidelines also widened the time window (6-24 hours after stroke onset) for performing mechanical thrombectomy among selected patients. Like the older version, however, the guidelines recommend mechanical thrombectomy be performed in an experienced stroke center (1).

Peer-review: Externally peer-reviewed.

Conflict of Interest: The author has no conflict of interest to declare.

Financial Disclosure: The author declared that this study has received no financial support.

\section{References}

1. Powers WJ, Rabinstein AA, Ackerson T, Adeoye OM, Bambakidis NC, Becker K, et al. 2018 Guidelines for the Early Management of Patients With Acute Ischemic Stroke: A Guideline for Healthcare Professionals From the American Heart Association/American Stroke Association. Stroke. 2018; 49: e46-e110. [CrossRef]

2. Nogueira RG, Jadhav AP, Haussen DC, Bonafe A, Budzik RF, Bhuva P, et al. Thrombectomy 6 to 24 Hours after Stroke with a Mismatch between Deficit and Infarct. N Engl J Med. 2018; 378: 11-21. [CrossRef]

3. Albers GW, Marks MP, Kemp S, Christensen S, Tsai JP, Ortega-Gutierrez S, et al. Thrombectomy for Stroke at 6 to 16 Hours with Selection by Perfusion Imaging. N Engl J Med. 2018; 378: 708-18. [CrossRef]

ORCID ID of the author: O.S. 0000-0003-3365-3713. 